\title{
Rapid Improvement of Severe Pulmonary Hypertension Due to Scoliosis-related Restrictive Ventilatory Disorder
}

\author{
Takashi Inao ${ }^{1,2}$, Masashi Amano ${ }^{3,4}$, Seishu Hashimoto ${ }^{2}$, Chisato Izumi ${ }^{3,4}$, Yodo Tamaki ${ }^{4}$, \\ Toshihiro Tamura ${ }^{4}$, Yoshio Taguchi ${ }^{2}$ and Takashi Hajiro ${ }^{2}$
}

\begin{abstract}
:
Few reports have highlighted the serial changes in pulmonary hypertension during respiratory management. An 18-year-old girl with severe scoliosis was referred to our hospital for worsening dyspnea on exertion. Based on chest X-ray and transthoracic echocardiography findings showing a tricuspid regurgitation pressure gradient (TRPG) of $64 \mathrm{mmHg}$, the patient was diagnosed with severe alveolar hypoventilation due to thoracic deformity and severe pulmonary hypertension. Her oxygenation improved rapidly under noninvasive positive pressure ventilation, although partial pressure of carbon dioxide remained $>80$ Torr. Transthoracic echocardiography on day 7 showed clinically significant and rapid improvement of pulmonary hypertension with a TRPG of $30 \mathrm{mmHg}$.
\end{abstract}

Key words: pulmonary hypertension, scoliosis, restrictive ventilatory disorder, ventilation-perfusion mismatch, hypoxemia, noninvasive positive pressure ventilation

(Intern Med 60: 3289-3293, 2021)

(DOI: 10.2169/internalmedicine.6525-20)

\section{Introduction}

In patients with scoliosis, chronic hypoxemia and type II (hypercapnic) respiratory failure are caused by thoracic deformity-related severe alveolar hypoventilation (1). Risks of cardiopulmonary complications (e.g., respiratory failure, right heart failure, and pulmonary hypertension) increase in patients with untreated and progressive ventilatory disorders $(2,3)$. To our knowledge, few reports have highlighted serial changes in pulmonary hypertension during respiratory management.

We herein report a patient who exhibited rapid improvement of severe pulmonary hypertension due to scoliosisrelated restrictive ventilatory disorder.

\section{Case Report}

An 18-year-old girl was referred to our hospital for the treatment of a headache and worsening dyspnea on exertion (especially early in the morning) without cough or a fever.
She had a medical history of Chiari type I malformation and syringomyelia that extended from the second cervical vertebra to the tenth thoracic vertebra; she had undergone foramen magnum decompression at seven years old. In addition, she had been diagnosed with scoliosis, and her coronal Cobb angle of curvature had worsened from $30^{\circ}$ at 7 years old to $40^{\circ}$ at 9 years old and then to $105^{\circ}$ at 13 years old. Surgical correction of scoliosis had been performed when the patient was 13 years old, and her Cobb angle had decreased to $62^{\circ}$ (Fig. 1).

On admission, the patient's height was $132 \mathrm{~cm}$, and her body weight was $22 \mathrm{~kg}$; her face was small because of scoliosis-related growth retardation. Her vital signs were as follows: blood pressure, 94/58 $\mathrm{mmHg}$; heart rate, 116 beats per minute; respiration rate, 20 breaths per minute; and oxygen saturation, $64 \%$ while breathing ambient air. The patient exhibited cyanosis but did not demonstrate leg edema or jugular venous dilatation. Her blood gas and laboratory measurements were as follows: $\mathrm{pH}, 7.233$; partial pressure of oxygen $\left(\mathrm{PaO}_{2}\right)$, 32.4 Torr; partial pressure of carbon dioxide $\left(\mathrm{PaCO}_{2}\right)$, 74.1 Torr; bicarbonate, $29.9 \mathrm{mmol} / \mathrm{L}$; Alveolar-

${ }^{1}$ Department of Respiratory Medicine, Shinko Hospital, Japan, ${ }^{2}$ Department of Respiratory Medicine, Tenri Hospital, Japan, ${ }^{3}$ Department of Cardiovascular Medicine, National Cerebral and Cardiovascular Center, Japan and ${ }^{4}$ Department of Cardiology, Tenri Hospital, Japan Received: October 15, 2020; Accepted: March 15, 2021; Advance Publication by J-STAGE: May 7, 2021 Correspondence to Dr. Takashi Inao, inao.takashi.2@gmail.com 

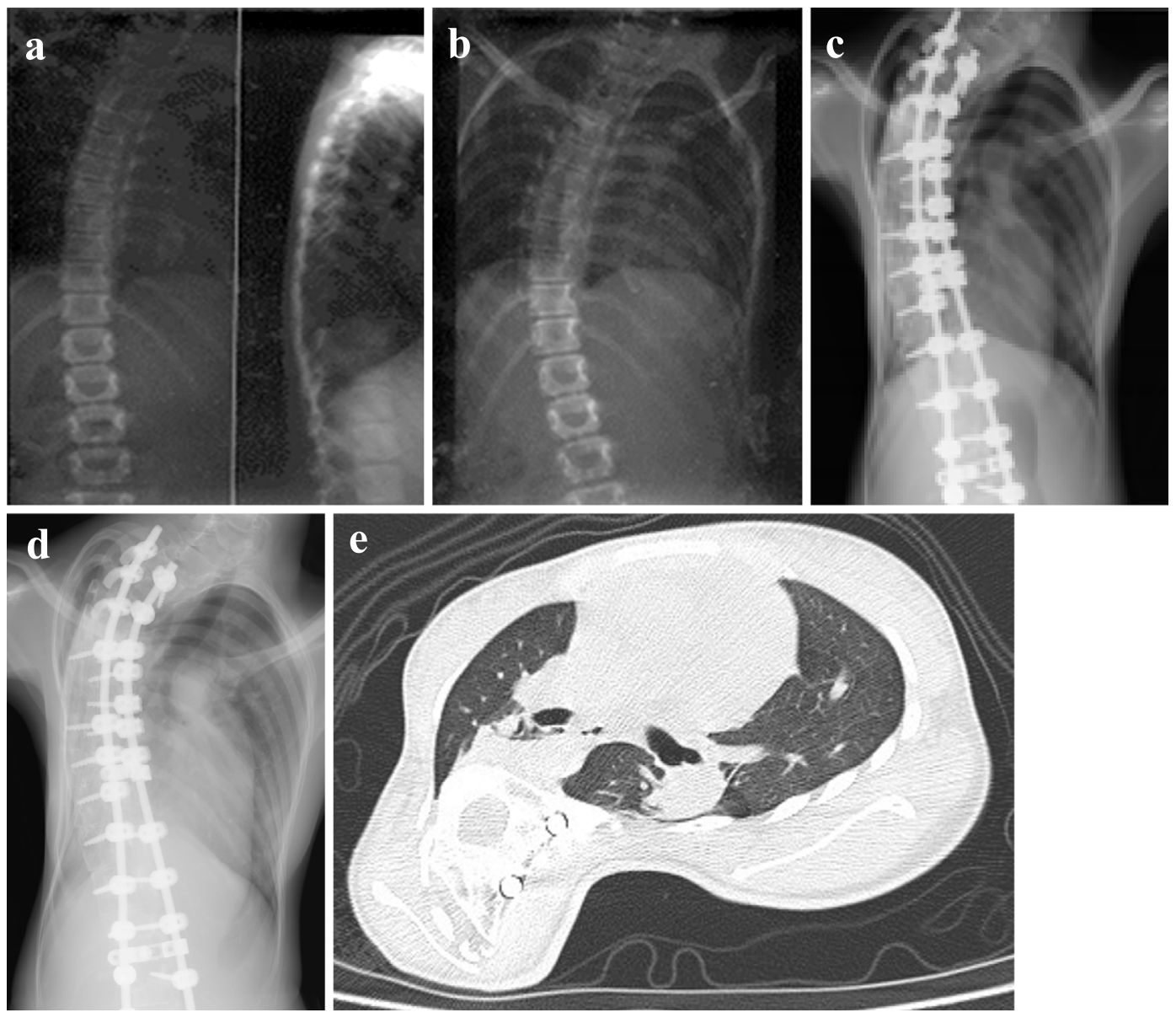

Figure 1. Serial changes in chest $\mathrm{X}$-ray radiographs, together with chest computed tomography findings on admission. Chest $\mathrm{X}$-ray radiographs of the patient: (a) at 7 years old, Cobb angle $30^{\circ}$; (b) at 9 years old, Cobb angle $40^{\circ}$; (c) at 13 years old after surgical correction for scoliosis, Cobb angle $62^{\circ}$; (d) on admission at 18 years old. (e) Chest computed tomography on admission: severe thoracic deformity, especially on the right side, and remarkable lung volume loss were evident in both thoracic cavities.

to-arterial oxygen gradient $\left(\mathrm{A}-\mathrm{aDO}_{2}\right), 24.7$ Torr; hemoglobin, $13.8 \mathrm{~g} / \mathrm{dL}$; C-reactive protein, $<0.2 \mathrm{mg} / \mathrm{dL}$; erythrocyte sedimentation rate, $1 \mathrm{~mm} / \mathrm{h}$; D-dimer, $1.3 \mu \mathrm{g} / \mathrm{mL}$; brain natriuretic peptide, $849 \mathrm{pg} / \mathrm{mL}$; and antinuclear antibody titer, $<1$ : 40.

Chest X-ray showed severe thoracic deformity, especially on the right side; chest computed tomography showed remarkable lung volume loss in both thoracic cavities (Fig. 1). Transthoracic echocardiography showed significant dilatation of the right ventricle and D-shape deformity of the left ventricle during systole, accompanied by a tricuspid regurgitation pressure gradient (TRPG) of $64 \mathrm{mmHg}$. However, 1 year prior to admission, no pulmonary hypertension had been detected by transthoracic echocardiography with a TRPG of $25 \mathrm{mmHg}$ (Fig. 2a-c). Therefore, we presumed that severe pulmonary hypertension had been caused by alveolar hypoventilation related to thoracic deformity during that one-year interval.

Because the patient's $\mathrm{PaCO}_{2}$ increased to 140 Torr immediately after admission, noninvasive positive pressure ventilation (NPPV) was initiated. Her oxygenation improved soon after initiation of NPPV, and a blood gas analysis showed that the $\mathrm{pH}$ increased from 7.233 to 7.309 , although the $\mathrm{PaCO}_{2}$ remained $>80$ Torr. Transthoracic echocardiography on day 7 showed marked improvement of right ventricular dilatation and left ventricular D-shape deformity, and TRPG decreased to $30 \mathrm{mmHg}$ (Fig. 2d-f). Right heart catheterization on the same day also revealed improvement of pulmonary hypertension without enhancement of the pulmonary capillary wedge pressure. The catheterization findings on ambient air were as follows: systolic pulmonary arterial pressure, $37 \mathrm{mmHg}$; mean pulmonary arterial pressure, 26 $\mathrm{mmHg}$; pulmonary capillary wedge pressure, $7 \mathrm{mmHg}$; cardiac output, $3.90 \mathrm{~L} / \mathrm{min}$; and pulmonary vascular resistance, 4.9 Wood units. We therefore concluded that the severe reversible pulmonary hypertension had been caused by worsening of hypoxia associated with severe alveolar hypoventilation and thoracic deformity.

Despite the above management, the patient's $\mathrm{PaCO}_{2}$ had not decreased to $<80$ Torr, and her headache persisted on day 10; her small face was presumed to be interfering with the appropriate fit of the ventilation mask, thereby reducing 

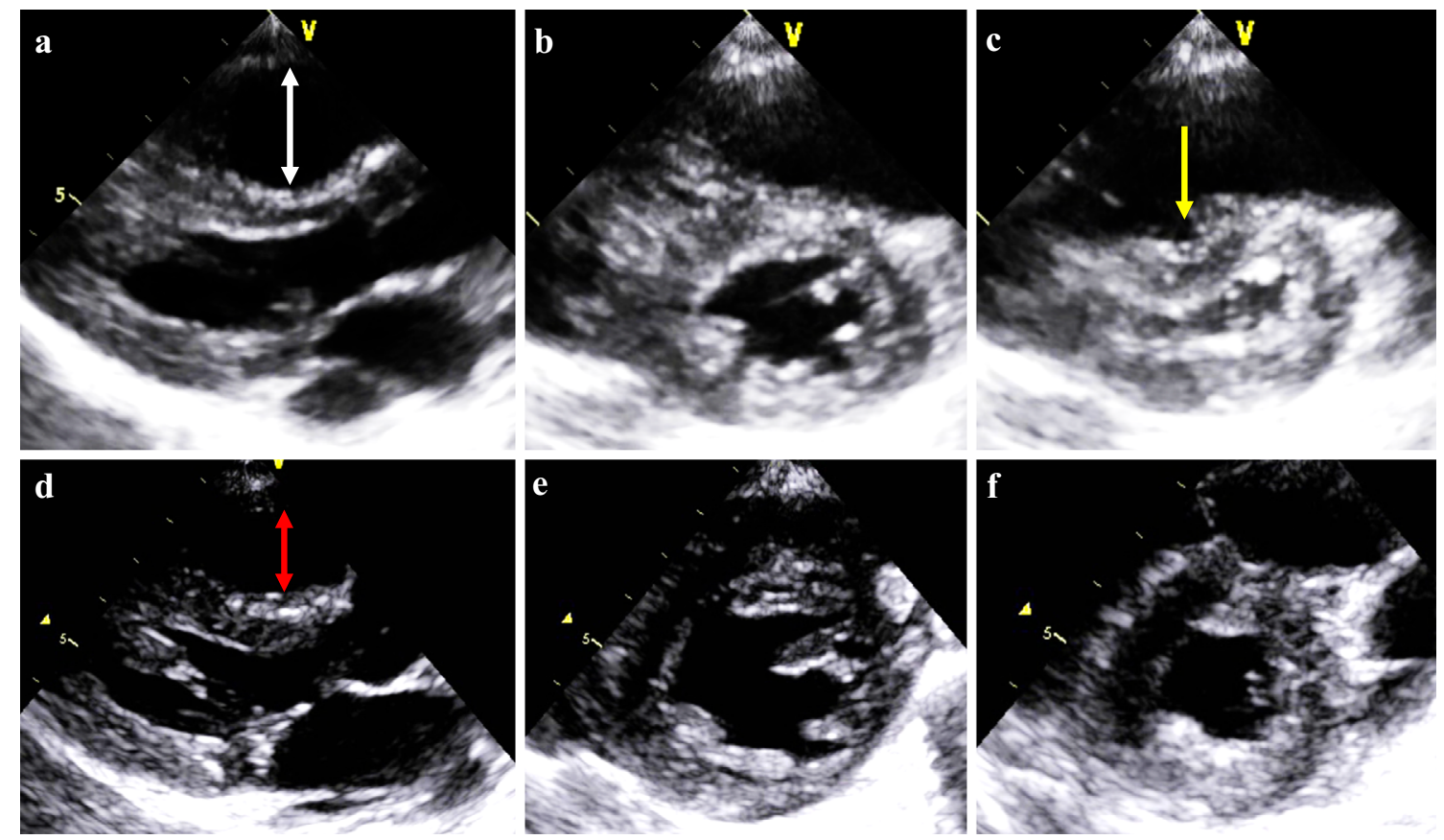

Figure 2. Serial changes in right ventricle pressure overload assessed by transthoracic echocardiography. (a-c) Transthoracic echocardiography on admission: (a) parasternal long-axis view, with substantial right ventricular dilatation $(24.1 \mathrm{~mm}$, white arrow); (b) parasternal short-axis view at end-diastole; (c) parasternal short-axis view at mid-systole, with severe interventricular septum compression. (d-f) Transthoracic echocardiography on day 7: (d) parasternal long-axis view, with improved right ventricular dilatation $(20.9 \mathrm{~mm}$, red arrow); (e) parasternal short-axis view at end-diastole; (f) parasternal short-axis view at mid-systole, with improvement of interventricular septum compression.

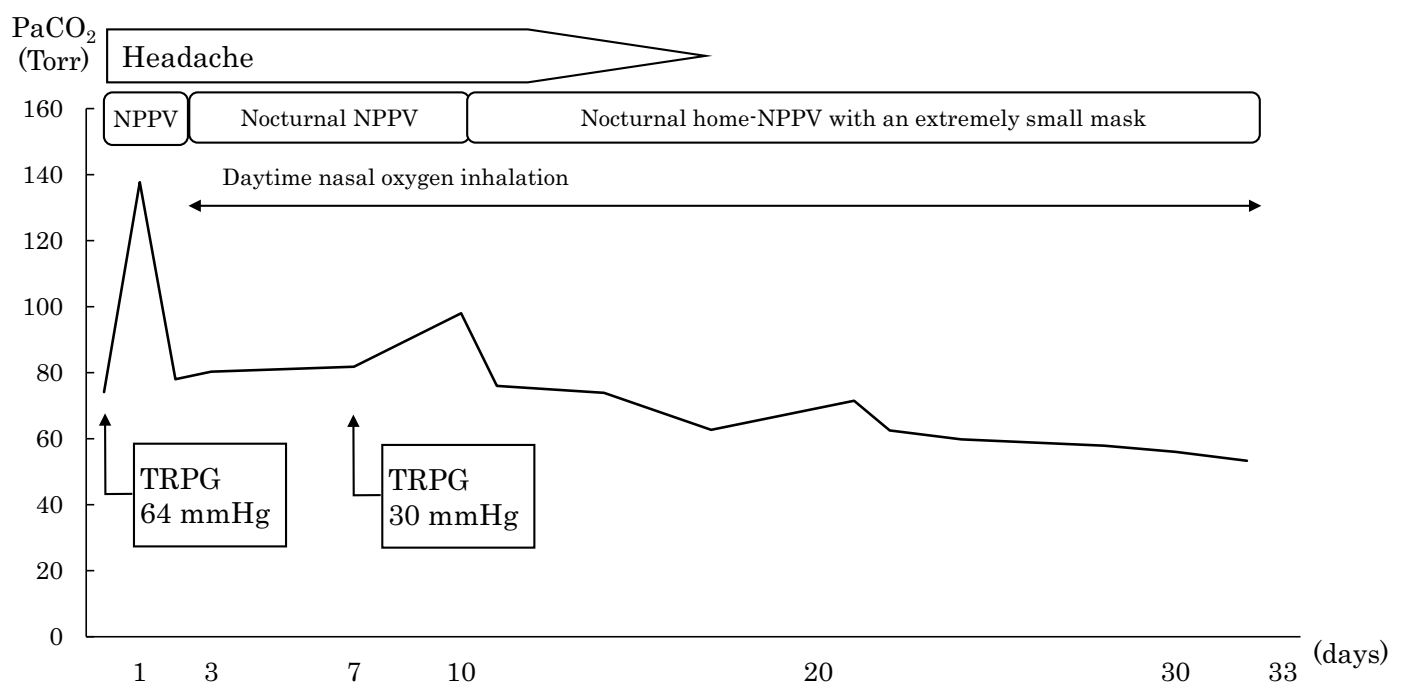

Figure 3. Changes in $\mathrm{PaCO}_{2}$ and headache after admission. On day 10, an extremely small mask for home-NPPV was implemented, which led to a reduction in the $\mathrm{PaCO}_{2}$. The patient's headache completely disappeared on day 17. NPPV: noninvasive positive pressure ventilation, $\mathrm{PaCO}_{2}$ : partial pressure of carbon dioxide, TRPG: tricuspid regurgitation pressure gradient

the effective ventilatory support provided by NPPV. In addition, backup ventilation of the NPPV apparatus was activated during the night, suggesting that the patient had experienced central apnea concomitant with severe alveolar hypoventilation. An extremely small mask (typically used for
home-NPPV) was then utilized to aid in effective breathing. This mask achieved an appropriate fit with the patient's small face; thus, her $\mathrm{PaCO}_{2}$ decreased to 53.3 Torr with a $\mathrm{PaO}_{2}$ of 60.6 Torr and 3.8 Torr of $\mathrm{A}-\mathrm{aDO}_{2}$, and her headache completely disappeared on day 17 (Fig. 3). The pulmonary 
functional test after improvement of her headache was as follows: vital capacity, $0.46 \mathrm{~L}$; total lung capacity, $1.16 \mathrm{~L}$; forced vital capacity, $0.46 \mathrm{~L}$; forced expiratory volume in one second, 0.35 L. Finally, the patient was discharged on day 33 with nocturnal home-NPPV.

\section{Discussion}

This report describes a rare instance in which severe pulmonary hypertension due to scoliosis-related restrictive ventilatory disorder showed rapid improvement with concomitant resolution of hypoxemia. Furthermore, an extremely small mask (typically used for home-NPPV) was able to provide effective ventilatory support and helped improve her hypercapnia and headache due to severe alveolar hypoventilation.

Chiari type I malformation was first described by Chiari et al. (4) in 1891 in patients who had a cerebellar tonsil hernia that extended beneath a foramen magnum greater than 5 $\mathrm{mm}$ (5). Syringomyelia and scoliosis are often present in affected patients. In our patient, scoliosis progressed severely despite surgical treatment for Chiari type I malformation; furthermore, severe thoracic deformity persisted despite surgical correction of scoliosis. Thus far, no clear relationship has been established between severity of scoliosis and the onset of pulmonary hypertension, although a mild association with scoliosis and pulmonary hypertension has been reported between the Cobb angle and systolic pulmonary arterial pressure (6). On the other hand, a relationship has been described between hypoxemia $\left(\mathrm{PaO}_{2}<70 \mathrm{mmHg}\right)$ and pulmonary hypertension (7). In our patient, severe pulmonary hypertension improved markedly with concomitant improvement of hypoxemia over a short period (one week). This rapid improvement in pulmonary hypertension with concomitant resolution of hypoxemia has already been reported in patients with chronic obstructive pulmonary disease (8). Therefore, in the present case, severe pulmonary hypertension might have been associated with hypoxemia.

The main causes of hypoxemia in patients with scoliosis are alveolar hypoventilation and thoracic deformity-related restrictive ventilatory disorder $(9,10)$. Patients with progressive congenital scoliosis exhibit disrupted development of alveoli and pulmonary arteries, which causes chronic hypoxemia (11). Localized ventilation-perfusion mismatch also contributes to hypoxemia. In patients with scoliosis, increasing deformity leads to greater reductions in both ventilation and perfusion in the base of the lung. However, ventilation is more severely impaired in the region of maximum convexity than in the concave side, while perfusion is unaffected by thoracic asymmetry $(12,13)$. Accordingly, regional alveolar hypoxia (caused by increase of ventilation-perfusion mismatch) induces pulmonary artery smooth muscle contraction to maintain the ventilation-perfusion ratio, thus resulting in elevation of pulmonary artery pressure $(14,15)$. Furthermore, respiratory acidosis on admission may be related to pulmonary vasoconstriction and temporary hypoxemia (16)
As another cause of pulmonary hypertension in patients with scoliosis, increased pulmonary vascular resistance due to a decreased number of vascular units per unit volume of lung and compression of lung by the rib-cage deformity has also been reported (17). In our patient, in addition to the increased pulmonary vascular resistance related to the thoracic deformity itself, restrictive ventilatory disorder-related hypoxemia, ventilation-perfusion mismatch, and respiratory acidosis mainly led to pulmonary artery contraction, which then resulted in severe pulmonary hypertension. Oxygen administration and ventilatory support by NPPV improved the hypoxemia in our patient, which might have rapidly reduced pulmonary artery pressure.

In the present patient, central apnea and chronic alveolar hypoventilation were regarded as the main causes of hypercapnia. In patients with Chiari I malformation, central apnea is caused by compression of the brain stem and neuronal structures due to herniation of cerebellar tonsils through the foramen magnum (18). Peripheral chemoreceptor sensitivity is also reportedly reduced, leading to decreasing ventilatory drive (19). Therefore, central apnea might have aggravated ventilatory disorder and type II respiratory failure in our patient. Furthermore, hypercapnia and headache persisted because of ineffective ventilatory support by NPPV as a result of a poor mask fit. Our findings indicate that switching to a smaller mask for home-NPPV may be useful for achieving effective ventilatory support in patients who exhibit growth retardation and a small face.

The authors state that they have no Conflict of Interest (COI).

\section{References}

1. Pehrsson K, Bake B, Larsson S, Nachemson A. Lung function in adult idiopathic scoliosis: a 20 year follow up. Thorax 46: 474478, 1991.

2. Nachemson A. A long term follow-up study of non-treated scoliosis. Acta Orthop Scand 39: 466-476, 1968.

3. Held M, Walthelm J, Baron S, Roth C, Jany B. Functional impact of pulmonary hypertension due to hypoventilation and changes under noninvasive ventilation. Eur Respir J 43: 156-165, 2014.

4. Chiari H. [On cerebellar changes due to hydrocephalus of the cerebrum]. Dtsch Med Wochenschr 17: 1172-1175, 1891 (in German).

5. Barkovich AJ, Wippold FJ, Sherman JL, Citrin CM. Significance of cerebellar tonsillar position on MR. AJNR Am J Neuroradiol 7: 795-799, 1986.

6. Li X, Li Z, Feng F, et al. Correlation between severity of adolescent idiopathic scoliosis and pulmonary artery systolic pressure: a study of 338 patients. Eur Spine J 25: 3180-3185, 2016.

7. Shneerson JM, Venco A, Prime FJ. A study of pulmonary artery pressure, electrocardiography, and mechanocardiography in thoracic scoliosis. Thorax 32: 700-705, 1977.

8. Weitzenblum E. Chronic cor pulmonale. Heart 89: 225-30, 2003.

9. Newton PO, Faro FD, Gollogly S, Betz RR, Lenke LG, Lowe TG. Results of preoperative pulmonary function testing of adolescents with idiopathic scoliosis. A study of six hundred and thirty-one patients. J Bone Joint Surg Am 87: 1937-1946, 2005.

10. Kearon C, Viviani GR, Kirkley A, Killian KJ. Factors determining pulmonary function in adolescent idiopathic thoracic scoliosis. Am 
Rev Respir Dis 148: 288-294, 1993.

11. Davies G, Reid L. Effect of scoliosis on growth of alveoli and pulmonary arteries and on right ventricle. Arch Dis Child 46: 623632, 1971.

12. Secker-Walker RH, Ho JE, Gill IS. Observations on regional ventilation and perfusion in kyphoscoliosis. Respiration 38: 194-203, 1979.

13. Giordano A, Fuso L, Galli M, et al. Evaluation of pulmonary ventilation and diaphragmatic movement in idiopathic scoliosis using radioaerosol ventilation scintigraphy. Nucl Med Commun 18: 105111, 1997.

14. Moudgil R, Michelakis ED, Archer SL. Hypoxic pulmonary vasoconstriction. J Appl Physiol (1985) 98: 390-403, 2005.

15. Voelkel NF. Mechanisms of hypoxic pulmonary vasoconstriction. Am Rev Respir Dis 133: 1186-1195, 1986.
16. Kregenow DA, Swenson ER. The lung and carbon dioxide: implications for permissive and therapeutic hypercapnia. Eur Respir $\mathrm{J}$ 20: 6-11, 2002.

17. Kafer ER. Respiratory and cardiovascular functions in scoliosis. Bull Eur Physiopathol Respir 13: 299-321, 1977.

18. Leu RM. Sleep-Related Breathing Disorders and the Chiari 1 Malformation. Chest 148: 1346-1352, 2015.

19. Bokinsky GE, Hudson LD, Weil JV. Impaired peripheral chemosensitivity and acute respiratory failure in Arnold-Chiari malformation and syringomyelia. N Engl J Med 288: 947-948, 1973.

The Internal Medicine is an Open Access journal distributed under the Creative Commons Attribution-NonCommercial-NoDerivatives 4.0 International License. To view the details of this license, please visit (https://creativecommons.org/licenses/ by-nc-nd/4.0/).

(C) 2021 The Japanese Society of Internal Medicine Intern Med 60: 3289-3293, 2021 